\title{
Sorafenib inhibits cancer side population cells by targeting c-Jun N-terminal kinase signaling
}

\author{
JONG BIN KIM ${ }^{1}$, MINJONG LEE ${ }^{1}$, SEO-YOUNG PARK ${ }^{2}$, SEULKI LEE ${ }^{1}$, HYE RI KIM ${ }^{1}$, \\ HYO-SUK LEE ${ }^{1}$, JUNG-HWAN YOON ${ }^{1}$ and YOON JUN KIM ${ }^{1}$ \\ ${ }^{1}$ Department of Internal Medicine and Liver Research Institute, Seoul National University College of Medicine; \\ ${ }^{2}$ Biomedical Research Institute, Seoul National University Hospital, Seoul 110-799, Republic of Korea
}

Received November 3, 2014; Accepted September 23, 2015

DOI: $10.3892 / \mathrm{mmr} .2015 .4422$

\begin{abstract}
Sorafenib is a systemic chemotherapeutic agent for advanced hepatocellular carcinoma (HCC). The aim of the present study was to evaluate the anticancer effect of sorafenib in cancer stem cell-like cells, such as side population (SP) cells, in HCC and to analyze the signaling pathway for drug-resistance. To evaluate the anticancer effects of sorafenib, Huh7 and Huh-BAT cells were treated with sorafenib, fluorouracil (5-FU), and sorafenib plus 5-FU. These cells were examined for growth rates, the SP fraction, sphere-forming efficacy and expression of c-Jun N-terminal kinase (JNK) signaling molecules. Sorafenib and 5-FU treatment decreased growth rates in Huh7 and Huh-BAT cells; however, the treatments exerted different effects in SP cells and on the expression levels of JNK signaling molecules. Treatment with 5-FU increased the SP cell number and upregulated the expression of JNK signaling molecules. By contrast, sorafenib decreased the SP cell number and downregulated the expression of JNK signaling molecules. No significant differences in sphere-forming efficacy were observed subsequent to 5-FU and sorafenib treatment in Huh7 and Huh-BAT cells. These results indicate that sorafenib exerted anticancer effects in HCC and SP cells by targeting JNK signaling.
\end{abstract}

\section{Introduction}

Hepatocellular carcinoma (HCC) has one of the highest mortality rates worldwide (1). HCC characteristics, such as strong resistance to anticancer drugs, local metastasis and heterogeneity, lead to complications in the effective treatment of HCC. Although multiple clinical trials to treat HCC through

Correspondence to: Professor Yoon Jun Kim, Department of Internal Medicine and Liver Research Institute, Seoul National University College of Medicine, 103 Daehak-ro, Seoul 110-799, Republic of Korea

E-mail: yoonjun@snu.ac.kr

Key words: hepatocellular carcinoma, sorafenib, cancer stem cells, side population, drug-resistance, c-Jun N-terminal kinase signaling systemic chemotherapy have been conducted, all treatments from Phase 3 clinical trials were unsuccessful, with the exception of sorafenib (2); however, it is not curative or approved by the US Food and Drug Administration (3). Sorafenib is a multiple kinase inhibitor, which blocks various signaling pathways involved in the proliferation of cancer cells (4) via the inhibition of multiple kinases, including mitogen-activated protein kinase (5), extracellular signal-regulated kinase (6), vascular endothelial growth factor receptor (7) and platelet-derived growth factor receptor (8).

Regarding the anticancer effects of combination therapy with sorafenib, it was reported that treatment with a combination of sorafenib, cisplatin and fluorouracil (5-FU) increased survival rates for metastatic nasopharyngeal carcinoma (9). In HCC, Petrini et al (10) reported that treatment with a combination of sorafenib and 5-FU improved the efficacy of systemic treatment in advanced $\mathrm{HCC}$ without side effects.

Cancer stem cells are known as tumor initiating cells (11) or anticancer drug-resistant cells (12). In HCC treatment, cancer stem cells are not easily eradicated due to their drug resistance and proliferative activity (13-15). HCC cancer stem cells that are resistant to chemotherapy positively express cluster of differentiation (CD)90, CD133 and ATP-binding cassette sub-family G member 2 (ABCG2) (16). Notably, ABCG2 expression was upregulated in HCC cells to remove the anticancer therapeutic agents from the cancer stem cells following treatment and was highly expressed in HCC tissues when compared with normal tissues (17). In addition, cancer stem cells induced c-Jun N-terminal kinase (JNK) and Wnt signaling interactions promoting their survival and proliferation in a model of colorectal carcinogenesis (18). In addition, Mucha et al (19) reported that JNK signaling was associated with TNF-related apoptosis-inducing ligand-induced cell death and resistance to apoptosis in HCC cells.

To date, to the best of our knowledge, there is a lack of studies regarding the anticancer effects of sorafenib-based combination therapies on cancer stem cells in HCC, particularly focusing on $\mathrm{ABCG} 2$ and JNK signaling in side population (SP) cells. In the present study, the anticancer effect of sorafenib was observed, with a focus on suppression of tumor initiating ability and drug-resistance in cancer stem cells. Specifically, growth rates in a fraction of SP cells, the expression of cancer stem cell markers, the efficacy of sphere-forming cells, and the 

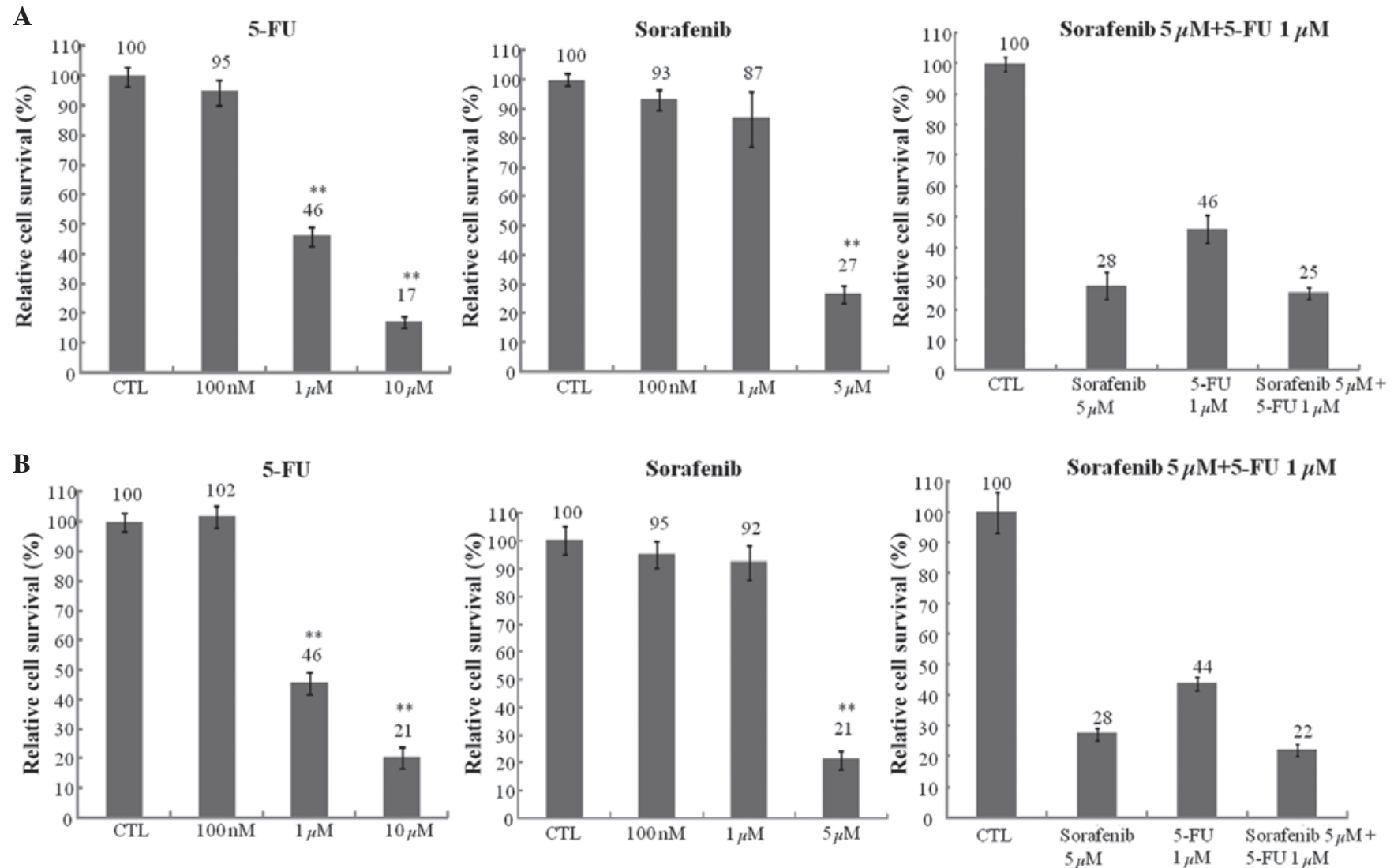

Figure 1. Growth rates in (A) Huh7 and (B) Huh-BAT cells following 5-FU and sorafenib treatment. Cells (5x10 ${ }^{5}$ ) were seeded in Dulbecco's modified Eagle's medium containing $10 \%$ fetal bovine serum. Cells were incubated for $72 \mathrm{~h}$ with 5 -FU, sorafenib or 5 -FU plus sorafenib. Growth rates were assessed by cell counting using trypan blue dye exclusion. Left panels: Cells were treated with distilled water (CTL), 1, 10 or $100 \mu \mathrm{M} 5$-FU; middle panels: Cells were treated with DMSO (CTL), $100 \mathrm{nM}, 1$ or $5 \mu \mathrm{M}$ sorafenib; right panels: Cells were treated with DMSO (control), $1 \mu \mathrm{M} 5$-FU, $5 \mu \mathrm{M}$ sorafenib or $1 \mu \mathrm{M} 5$-FU plus $5 \mu \mathrm{M}$ sorafenib. The relative cell survival rate is presented as relative survival versus the CTL cells. Values are presented as the mean \pm standard error from at least three independent experiments. ${ }^{*} \mathrm{P} \leq 0.05,{ }^{* *} \mathrm{P} \leq 0.01$, vs. the control group. 5-FU, fluorouracil; DMSO, dimethyl sulfoxide; CTL, control.

expression of relevant signaling molecules following sorafenib and 5-FU treatment were assessed.

\section{Materials and methods}

Cell culture. Huh7 and Huh-BAT cells (Korean Cell Line Bank, Seoul, Korea) were cultured in Dulbecco's modified Eagle's medium (DMEM; Gibco Life Technologies, Carlsbad, CA, USA) containing 10\% fetal bovine serum (FBS; Gibco Life Technologies). For adherent cultures, $5 \times 10^{5}$ cells were seeded on tissue culture dishes (Falcon, San Jose, CA, USA). All cultures were maintained at $37^{\circ} \mathrm{C}$ in a humidified $5 \% \mathrm{CO}_{2}$ atmosphere.

Growth rate following 5-FU and sorafenib treatment. Cells $\left(5 \times 10^{5}\right.$ cells) were seeded in DMEM containing $10 \%$ FBS. After $24 \mathrm{~h}$, the cells were washed twice with phosphate-buffered saline (PBS) and fresh media was added. Cells were treated for $72 \mathrm{~h}$ with distilled water (control), $100 \mathrm{nM}, 1$ or $10 \mu \mathrm{M} 5$-FU (Sigma-Aldrich, St. Louis, MO, USA) or $100 \mathrm{nM}, 1$ or $5 \mu \mathrm{M}$ of sorafenib (LC Laboratories, Woburn, MA, USA). Growth rates were estimated by the number of viable cells counted by positive staining with $0.4 \%$ trypan blue dye (Gibco Life Technologies) in a Neubauer chamber (Marienfeld-Superior, Lauda-Königshofen, Germany) with an inverted microscope (IX51; Olympus Corporation, Tokyo, Japan) equipped with a DP50 camera system (Olympus Corporation) at $72 \mathrm{~h}$ time points. Selected cells treated with $1 \mu \mathrm{M} 5-\mathrm{FU}$ or $5 \mu \mathrm{M}$ sorafenib were used to observe cell death, the cell cycle, SP cells, stem cell markers (CD44, CD24 and CD133), and JNK signaling molecules subsequent to treatment with these therapeutic agents.

Sphere-formation assay. Cells (1,000 per well) were seeded on Poly-HEMA-coated 96-well plates (Sigma-Aldrich) in DMEM containing $10 \%$ FBS. Cells were incubated for seven days with dimethyl sulfoxide (DMSO; Sigma-Aldrich; control), $1 \mu \mathrm{M}$ 5-FU, $3 \mu \mathrm{M}$ sorafenib or $1 \mu \mathrm{M} 5$-FU plus $3 \mu \mathrm{M}$ sorafenib. The number of spheres in each well was counted after seven days.

SP cell analyses. Cells ( $5 \times 10^{5}$ cells) were seeded in DMEM containing $10 \%$ FBS. After $24 \mathrm{~h}$, the cells were washed twice with PBS and fresh media was added. Cells were treated for $72 \mathrm{~h}$ with distilled water (control), $1 \mu \mathrm{M} 5$-FU or $5 \mu \mathrm{M}$ sorafenib. SP cell analyses were performed as reported previously (20). Cells were detached and collected in the form of cell pellets. To analyze the SP fraction, $1 \times 10^{6}$ cells $/ \mathrm{ml}$ were incubated for $90 \mathrm{~min}$ at $37^{\circ} \mathrm{C}$ before vortexing at maximum speed with Hoechst 33342 dye $(5 \mu \mathrm{g} / \mathrm{ml}$; Sigma-Aldrich) in DMEM containing 10\% FBS. The cells were also incubated with Hoechst dye and 50-100 $\mu \mathrm{M}$ verapamil (Sigma-Aldrich), an efflux blocker, to confirm the SP cell population. At the end 

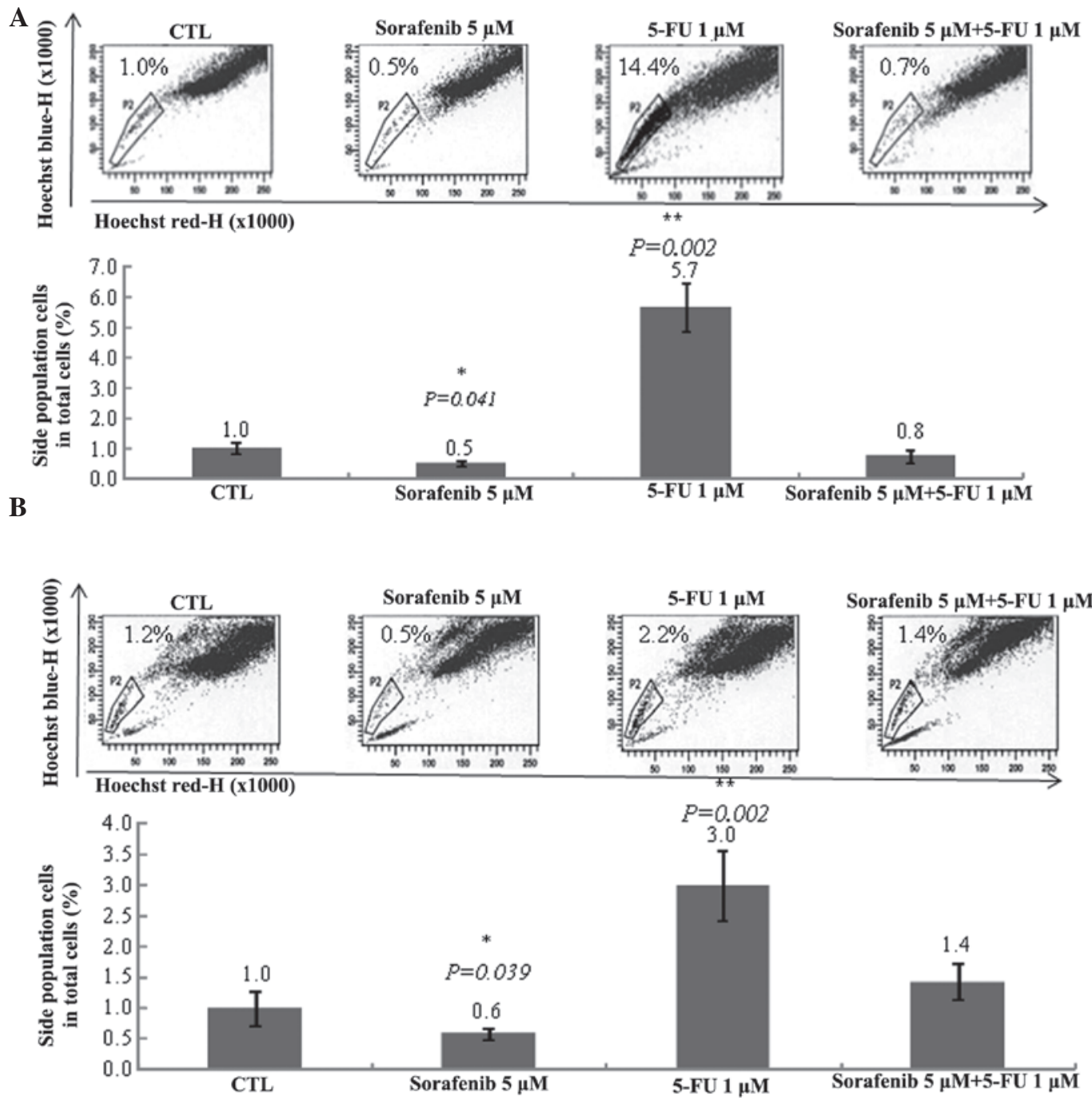

Figure 2. SP cells in (A) Huh7 and (B) Huh-BAT cells following 5-FU and sorafenib treatment. Huh7 or Huh-BAT cells (5x10 ${ }^{5}$ ) were seeded in Dulbecco's modified Eagle's medium containing $10 \%$ fetal bovine serum. The cells were incubated for $72 \mathrm{~h}$ with dimethyl sulfoxide (CTL), $1 \mu \mathrm{M} 5$-FU, $5 \mu \mathrm{M}$ sorafenib or $1 \mu \mathrm{M}$ 5-FU plus $5 \mu \mathrm{M}$ sorafenib. SP cells were assayed using a FACSAria with a 515-nm SP filter (Hoechst blue). Values are presented as the mean \pm standard error from at least three independent experiments. "P $\leq 0.05$, vs. the control group; ${ }^{* *} \mathrm{P} \leq 0.01$, vs. the $5 \mu \mathrm{M}$ sorafenib-treated group. SP, side population; 5 -FU, fluorouracil; CTL, control.

of the incubation, these cells were centrifuged at $80 \mathrm{x} g$ and $4^{\circ} \mathrm{C}$ for $3 \mathrm{~min}$ and collected for analysis of the SP fraction. Propidium iodide (1 $\mu \mathrm{g} / \mathrm{ml}$; Sigma-Aldrich) was added before fluorescence-activated cell sorting (FACS) analysis to identify and exclude the dead cells. Samples were analyzed using a FACSAria $^{\mathrm{TM}}$ II (BD Biosciences, Franklin Lakes, NJ, USA).

Immunoblotting. Cells $\left(5 \times 10^{5}\right.$ cells) were seeded in DMEM containing $10 \%$ FBS. After $24 \mathrm{~h}$, the cells were washed twice with PBS and fresh media was added. Cells were treated for $72 \mathrm{~h}$ with distilled water (control), $1 \mu \mathrm{M} 5$-FU or $5 \mu \mathrm{M}$ sorafenib. Total cell lysates were prepared in $100 \mu 1$ lysis buffer (Cell Signaling Technology, Inc., Danvers, MA, USA). Protein concentrations were measured using a Bio-Rad Protein Assay kit (Bio-Rad Laboratories Inc., Hercules, CA, USA). Equal quantities of cell lysates were separated using $10 \%$ sodium dodecyl sulfate-polyacrylamide gel electrophoresis (Bio-Rad Laboratories, Inc.) and proteins were electrotransferred to Hybond-ECL nitrocellulose membranes (GE Healthcare Life Sciences, Chalfont, UK). Blots were blocked for $1 \mathrm{~h}$ with blocking buffer (5\% skim milk) and incubated overnight at $4^{\circ} \mathrm{C}$ with anti-ABCG2 mouse monoclonal antibodies (1:1,000; cat. no. MABN1108; EMD Millipore, Billerica, MA, USA), anti-SAPK/JNK mouse monoclonal antibodies (1:1,000; cat. no. 9252; Cell Signaling Technology, Inc.), anti-phosphorylated (P)-SAPK/JNK (Thr183/Tyr185) mouse monoclonal antibodies (1:1,000; cat. no. 9255; Cell Signaling Technology, Inc.), c-Jun mouse monoclonal antibodies (1:1,000; cat. no. 2315; Cell Signaling Technology, Inc.), P-c-Jun (ser63) rabbit polyclonal antibodies $(1: 1,000$; cat. no. 2361 ; Cell Signaling Technology, Inc.) and anti- $\beta$-actin mouse monoclonal antibodies (1:1,000; cat. no. sc-47778; Santa Cruz Biotechnology, Inc., Dallas, TX, USA). Blots were washed with Tris-buffered saline containing $0.2 \%$ Tween-20 (Sigma-Aldrich) and incubated for $1 \mathrm{~h}$ at room temperature with peroxidase-conjugated AffiniPure rabbit anti-mouse immunoglobulin (Ig)G (1:2,500; cat. no. 315-005-045; Jackson ImmunoResearch Laboratories, Inc., West Grove, PA, USA) or peroxidase-conjugated AffiniPure mouse anti-rabbit IgG (1:2,500; cat. no. 211-005-109; Jackson ImmunoResearch Laboratories, Inc.). Labeled proteins were 

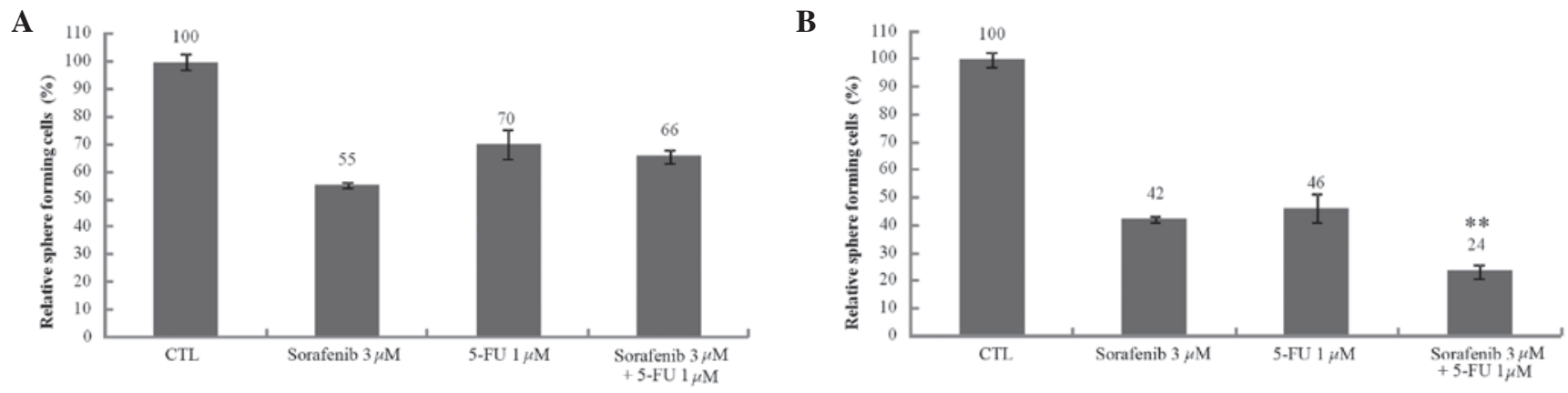

Figure 3. Sphere-forming cells in (A) Huh7 and (B) Huh-BAT cells following 5-FU and sorafenib treatment. Huh7 or Huh-BAT cells (1,000 cells/well) were seeded into Poly-HEMA-coated 96-well plates in Dulbecco's modified Eagle's medium containing 10\% fetal bovine serum. Cells were incubated for seven days with dimethyl sulfoxide (CTL), $1 \mu \mathrm{M}$ 5-FU, $3 \mu \mathrm{M}$ sorafenib or $1 \mu \mathrm{M} 5$-FU plus $3 \mu \mathrm{M}$ sorafenib. The number of spheres in each well was counted after seven days. The relative rate of sphere-forming cells is shown as the percentage of sphere-forming cells versus CTL cells. Values are presented as the mean \pm standard error from at least three independent experiments. ${ }^{*} \mathrm{P} \leq 0.05,{ }^{* *} \mathrm{P} \leq 0.01$ vs. the control group. 5 -FU, fluorouracil; CTL, control.

A

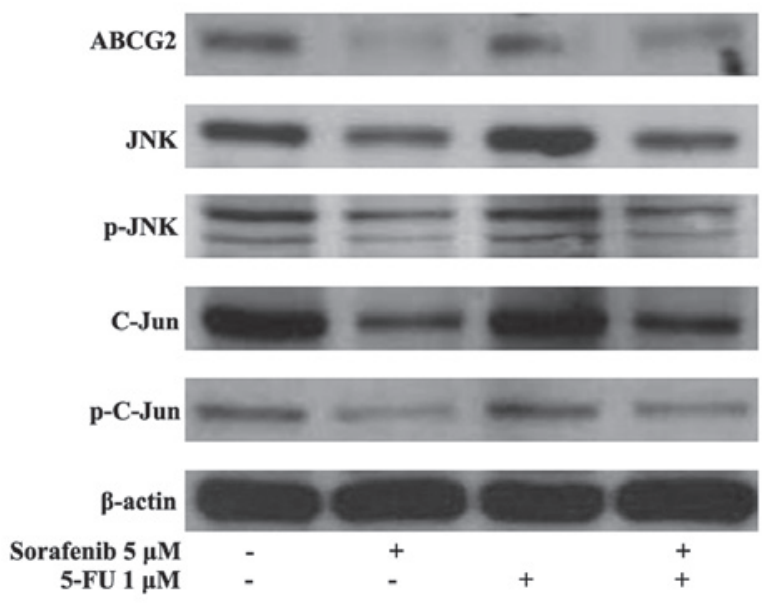

B

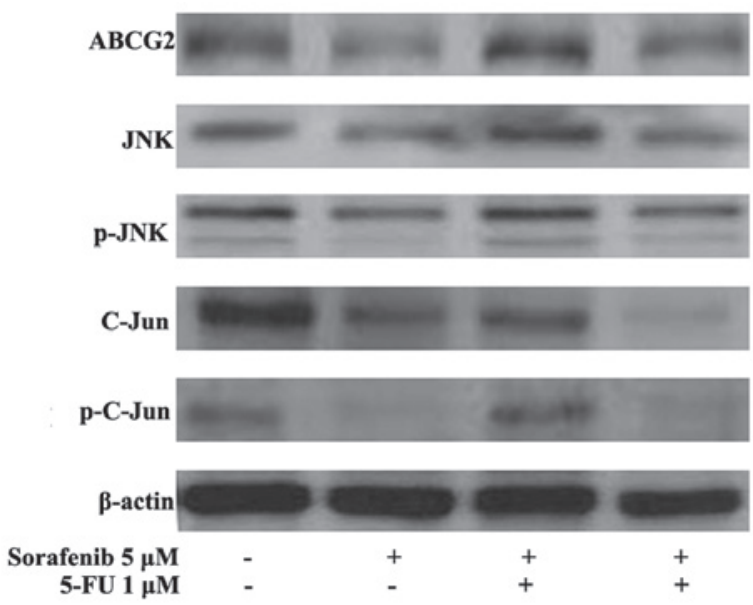

Figure 4. Expression of JNK signaling molecules (JNK, P-SAPK/JNK, c-Jun, and P-c-Jun) in Huh7 and Huh-BAT cells following 5-FU and sorafenib treatment. (A) Huh7 or (B) Huh-BAT cells $\left(5 \times 10^{5}\right)$ were seeded in Dulbecco's modified Eagle's medium containing $10 \%$ fetal bovine serum. Cells were incubated for $72 \mathrm{~h}$ with DMSO (CTL), $1 \mu \mathrm{M}$ 5-FU, $5 \mu \mathrm{M}$ sorafenib, or $1 \mu \mathrm{M}$ 5-FU plus $5 \mu \mathrm{M}$ sorafenib. Expression levels of ABCG2, JNK, P-JNK, c-Jun, and P-c-Jun were detected by immunoblotting. Cells were treated with distilled water and DMSO (lane 1), $5 \mu \mathrm{M}$ sorafenib (lane 2), $1 \mu \mathrm{M} 5$-FU (lane 3), or $5 \mu \mathrm{M}$ sorafenib plus $1 \mu \mathrm{M}$ 5-FU (lane 4). JNK, c-Jun N-terminal kinase; SAPK, stress-activated protein kinases; P, phosphorylated; 5-FU, fluorouracil; DMSO, dimethyl sulfoxide; ABCG2, ATP-binding cassette sub-family G member 2; CTL, control.

detected using an enhanced chemiluminescence detection system (GE Healthcare Life Sciences).

Statistical analyses. At least three replicate experiments were performed for all analyses. Data were expressed as the mean \pm standard error. Student's t-tests were applied to compare the results of the treated and control cells. $\mathrm{P}<0.05$ was considered to indicate a statistically significant difference.

\section{Results}

5-FU and sorafenib treatment decreases Huh7 and Huh-BAT cell growth rate. To observe the effect of 5-FU and sorafenib treatment on growth rates in Huh7 and Huh-BAT cells after $72 \mathrm{~h}$, cells were treated with various concentrations of 5-FU and sorafenib, as indicated in Fig. 1A and B. Growth rates of Huh7 and Huh-BAT cells were reduced by 5 -FU or sorafenib treatment in a dose-dependent manner (Fig. 1A and B; left and middle panel). Based on these results, $1 \mu \mathrm{M} \mathrm{5-FU}$ and $5 \mu \mathrm{M}$ sorafenib were selected to observe the synergistic anticancer growth rate effects in the Huh7 and Huh-BAT cells. The cells were treated with $1 \mu \mathrm{M} 5$-FU, $5 \mu \mathrm{M}$ sorafenib or $1 \mu \mathrm{M} 5$-FU plus $5 \mu \mathrm{M}$ sorafenib for $72 \mathrm{~h}$. However, a synergistic anticancer effect on growth rates resulting from treatment with $1 \mu \mathrm{M} 5-\mathrm{FU}$ plus $5 \mu \mathrm{M}$ sorafenib treatment was not observed in the cells (Fig. 1A and B; right panel).

Sorafenib decreases and 5-FU increases the number of SP cells. To determine the effect of 5-FU and sorafenib treatment against cancer stem cells induced from Huh7 and Huh-BAT cells, SP cells were analyzed using Hoechst dye staining followed by flow cytometry. Sorafenib reduced the number of SP cells, whereas 5-FU significantly increased SP cell number (Fig. 2). Furthermore, sorafenib plus 5-FU treatment blocked the 5-FU-mediated increase in SP cell number (Fig. 2). These results demonstrate that sorafenib may reduce growth rates by targeting cancer stem cells.

5-FU and sorafenib decrease the number of Huh7 and Huh-BAT sphere-forming cells. Sphere-forming cells have 
been proposed as a model for investigating cancer stem cells (21). It was observed that SP cell number was decreased following sorafenib treatment and increased following 5-FU treatment. To confirm the effect of these therapeutic agents against SP cells, sphere-forming cells were observed following 5-FU and sorafenib treatment in Huh7 and Huh-BAT cells. The number of sphere-forming cells decreased subsequent to 5-FU and sorafenib treatment compared with the controls (Fig. 3A and B). No significant differences were identified in the 5-FU, sorafenib or 5-FU plus sorafenib treatment groups in Huh7 cells (Fig. 3A). However, a difference was observed between Huh7 and Huh-BAT cells in the sphere-forming assay. The number of sphere-forming cells decreased following 5-FU plus sorafenib treatment compared with 5-FU and sorafenib treatments alone in the Huh-BAT cells (Fig. 3B). These results demonstrate that sphere-forming ability is dependent on varied conditions, such as cell type and therapeutic agent treatment.

Expression of ABCG2 and JNK signaling molecules are downregulated in Huh7 and Huh-BAT cells following sorafenib treatment. The expression of ABCG2, which is associated with drug-resistance, and JNK signaling molecules, including JNK, P-SAPK/JNK, c-Jun, and P-c-Jun, in Huh7 and Huh-BAT cells subsequent to 5-FU and sorafenib treatments was examined. The expression of ABCG2 and JNK signaling molecules (JNK, P-SAPK/JNK, c-Jun and P-c-Jun) was downregulated by sorafenib treatment and sorafenib plus 5 -FU treatment in the Huh-7 (Fig. 4A) and Huh-BAT cells (Fig. 4B).

\section{Discussion}

The present study hypothesized that sorafenib induced anticancer effects on cancer stem cells by blocking ABCG2 transporters and JNK signaling. It was further assessed whether the anticancer effects of sorafenib were fortified when combined with conventionally administered anticancer therapeutic agents, such as 5-FU. In the current study, sorafenib decreased the SP fraction, while 5-FU increased the SP fraction in two HCC cell lines. A combination treatment of 5-FU plus sorafenib further decreased the sphere-forming efficacy of Huh-BAT cells when compared with sorafenib or 5-FU treatment alone. In addition, the expression of ABCG2 and JNK signaling molecules was identified to be downregulated by sorafenib or 5-FU plus sorafenib treatment. These results indicate that sorafenib induces anticancer effects in SP cells via the inhibition of JNK signaling and ABCG2 transporters. Although synergistic anticancer effects on tumor growth rates following treatment with sorafenib plus 5-FU in HCC cells were not observed, the results indicate that sorafenib treatment may provide a novel therapeutic strategy for inducing anticancer effects in cancer stem cells.

According to the cancer stem cell hypothesis, initiation, aggressive progression, recurrence, metastasis and drug resistance are unique properties implicit in cancer stem cells. Thus, targeting cancer stem cells may present important clinical implications for the effective treatment of HCC. Current strategies are focused on targeting rapidly proliferating cancer cells, rather than cancer stem cells. Treatments may initially appear to be successful, however often fail to provide a long-lasting cure for the disease. This may be due to the heterogeneity of certain types of cancer, which contain different cell lines with varying sensitivities, or due to failing to eradicate the cancer stem cell population, leading to disease recurrence and tumor progression (22).

The current study indicates that, although sorafenib monotherapy is effective, the patterns of response vary between the SP and non-SP cell lines. This result may demonstrate the superior efficacy of sorafenib for treating advanced HCC in the clinical setting, as it effectively kills cancer stem cells. Lee et al (23) reported that treatment using sorafenib plus radiation inhibits growth by targeting cancer stem cells in breast cancer. Furthermore, Carra et al (24) reported that sorafenib induces cell death by targeting glioblastoma stem cells in human glioblastoma.

In conclusion, sorafenib and conventionally-used anticancer therapeutic agents inhibit cancer cell growth. However, treatment with sorafenib alone decreased cancer stem cell numbers, their sphere-forming efficacy, expression of ABCG2, and JNK signaling, all of which are involved in drug resistance. These results indicate that sorafenib is effective as an anticancer therapeutic agent against HCC cancer stem cells and affects the signaling pathways involved in drug resistance.

\section{Acknowledgements}

The present study was supported by grants from Ildong Pharmaceutical Co., Ltd. (Seoul, South Korea) (grant no. S72-06001) and the Han Wha Pharma Co., Ltd. (Seoul, South Korea) [grant no. 0620141500 (2014-1516)].

\section{References}

1. El-Serag HB: Hepatocellular carcinoma. N Engl J Med 365: 1118-1127, 2011.

2. Llovet JM, Ricci S, Mazzaferro V, Hilgard P, Gane E, Blanc JD, de Oliveira AC, Santoro A, Raoul JL, Forner A, et al: Sorafenib in advanced hepatocellular carcinoma. New Engl J Med 359: 378-390, 2008

3. Lang L: FDA approves sorafenib for patients with inoperable liver cancer. Gastroenterology 134: 379, 2008.

4. Kane RC, Farrell AT, Saber H, Tang S, Williams G, Jee JM, Liang C, Booth B, Chidambaram N, Morse D, et al: Sorafenib for the treatment of advanced renal cell carcinoma. Clin Cancer Res 12: 7271-7278, 2006.

5. Min L, He B and Hui L: Mitogen-activated protein kinases in hepatocellular carcinoma development. Semin Cancer Biol 21: 10-20, 2011.

6. Wilhelm SM, Carter C, Tang L, Wilkie D, McNabola A, Rong H, Chen C, Zhang X, Vincent P, McHugh M, et al: BAY 43-9006 exhibits broad spectrum oral antitumor activity and targets the RAF/MEK/ERK pathway and receptor tyrosine kinases involved in tumor progression and angiogenesis. Cancer Res 64: 7099-7109, 2004

7. Scartozzi M, Faloppi L, Svegliati Baroni G, Loretelli C, Piscaglia F, Iavarone M, Toniutto P, Fava G, De Minicis S, Mandolesi A, et al: VEGF and VEGFR genotyping in the prediction of clinical outcome for HCC patients receiving sorafenib: The ALICE-1 study. Int J Cancer 135: 1247-1256, 2014.

8. Liu L, Cao Y, Chen C, Zhang X, McNabola A, Wilkie D, Wilhelm S, Lynch $M$ and Carter C: Sorafenib blocks the RAF/MEK/ERK pathway, inhibits tumor angiogenesis, and induces tumor cell apoptosis in hepatocellular carcinoma model PLC/PRF/5. Cancer Res 66: 11851-11858, 2006.

9. Xue C, Huang Y, Huang PY, Yu QT, Pan JJ, Liu LZ, Song XQ, Lin SJ, Wu JX, Zhang JW, et al: Phase II study of sorafenib in combination with cisplatin and 5-fluorouracil to treat recurrent or metastatic nasopharyngeal carcinoma. Ann Oncol 24: 1055-1061, 2013. 
10. Petrini I, Lencioni M, Ricasoli M, Iannopollo M, Orlandini C, Oliveri F, Bartolozzi C and Ricci S: Phase II trial of sorafenib in combination with 5-fluorouracil infusion in advanced hepatocellular carcinoma. Cancer Chemother Pharmacol 69: 773-780, 2012.

11. Bonnet D and Dick JE: Human acute myeloid leukemia is organized as a hierarchy that originates from a primitive hematopoietic cell. Nat Med 3: 730-737, 1997.

12. Reya T, Morrison SJ, Clarke MF and Weissman IL: Stem cells, cancer, and cancer stem cells. Nature 414: 105-111, 2001.

13. Seki E, Brenner DA and Karin M: A liver full of JNK: Signaling in regulation of cell function and disease pathogenesis, and clinical approaches. Gastroenterology 143: 307-320, 2012.

14. Telbisz A, Hegedüs C, Váradi A, Sarkadi B, and Özvegy-Laczka C: Regulation of the function of the human ABCG2 multidrug transporter by cholesterol and bile acids: Effects of mutations in potential substrate and steroid binding sites. Drug Metab Dispos 42: 575-585, 2014.

15. Yoon CH, Kim MJ, Kim RK, Lim EJ, Choi KS, An S, Hwang SG, Kang SG, Suh Y, Park MJ and Lee SJ: c-Jun N-terminal kinase has a pivotal role in the maintenance of self-renewal and tumorigenicity in glioma stem-like cells. Oncogene 31: 4655-4666, 2012.

16. Jia Q, Zhang X, Deng T and Gao J: Positive correlation of Oct4 and ABCG2 to chemotherapeutic resistance in CD90( ${ }^{+}$ CD133( $\left(^{+}\right)$liver cancer stem cells. Cell Reprogram 15: 143-150, 2013.
17. Sukowati CH, Rosso N, Pascut D, Anfuso B, Torre G, Francalanci P, Crocè LS and Tiribelli C: Gene and functional up-regulation of the BCRP/ABCG2 transporter in hepatocellular carcinoma. BMC Gastroenterol 12: 160, 2012.

18. Sancho R, Nateri AS, de Vinuesa AG, Aguilera C, Nye E, Spencer-Dene B and Behrens A: JNK signalling modulates intestinal homeostasis and tumourigenesis in mice. EMBO J 28: 1843-1854, 2009.

19. Mucha SR, Rizzani A, Gerbes AL, Camaj P, Thasler WE, Bruns CJ, Eichhorst ST, Gallmeier E, Kolligs FT, Göke B and De Toni EN: JNK inhibition sensitises hepatocellular carcinoma cells but not normal hepatocytes to the TNF-related apoptosis-inducing ligand. Gut 58: 688-698, 2009.

20. Goodell MA: Multipotential stem cells and 'side population' cells. Cytotherapy 4: 507-508, 2002.

21. Qiu X, Wang Z, Li Y, Miao Y, Ren Y and Luan Y: Characterization of sphere-forming cells with stem-like properties from the small cell lung cancer cell line H446. Cancer Lett 323: 161-170, 2012.

22. Ma S: Biology and clinical implications of $\mathrm{CD} 133\left(^{+}\right)$liver cancer stem cells. Exp Cell Res 319: 126-132, 2013.

23. Lee JH, Shim JW, Choi YJ, Heo K and Yang K: The combination of sorafenib and radiation preferentially inhibits breast cancer stem cells by suppressing HIF-1 $\alpha$ expression. Oncol Rep 29: 917-924, 2013.

24. Carra E, Barbieri F, Marubbi D, Pattarozzi A, Favoni RE, Florio T and Daga A: Sorafenib selectively depletes human glioblastoma tumor-initiating cells from primary cultures. Cell Cycle 12: 491-500, 2013. 